\title{
Uma proposta para a presença curricular da geometria das transformações
}

\author{
Adlai Ralph Detoni \\ Doutor em Educação Matemática
}

\author{
Débora Bordonal Senra Oliveira \\ Mestre em Educação Matemática
}

\begin{abstract}
Resumo
Este artigo traz resultados de uma pesquisa realizada que abordou a Geometria das Transformações, objetivando refletir sobre suas possibilidades de estar presente nas práticas curriculares da Geometria Escolar. Apresenta parte da revisão bibliográfica feita nos estudos dos autores, compreendendo propostas de alguns estudiosos brasileiros de alternativas ao que tradicionalmente se observa em nossas salas de aula. Junto a contribuições da literatura, apresentam-se as articulações que os autores constituíram para a prática geométrica em ambiente investigativo mediada por um software gráfico, a partir de um grupo de aprendizes em atitude colaborativa. Justifica-se uma pesquisa de campo realizada junto a licenciandos, toda ela pensada e analisada em seus dados com fundamentação metodológica na Fenomenologia. Com as análises convergentes para grupos compreensivos de ideias manifestadas pelos sujeitos, fazem-se considerações conclusivas quanto à pertinência das intenções propostas, entendendose novos valores pedagógicos, epistemológicos e didáticos.
\end{abstract}

Palavras-chave: Geometria das Transformações, Fenomenologia, Investigação, Colaboração, Software Gráfico.

\section{A proposal for the curricular presence of transformation geometry}

\begin{abstract}
In this paper, we present the results of a research on Transformation Geometry, aiming to contribute to the reflection on its possible presence in the curricular practices of School Geometry. We have included a part of the bibliographic review made in the authors' studies, understanding the proposals of some Brazilian scholars regarding alternatives to what is traditionally seen in our classes. Along with literature contributions, we present the articulations we made for the Geometry practice on an investigation environment facilitated by a graphic software in groups of collaborative learners. We substantiate the fieldwork research carried out with Education undergraduate students, with its planning and data analyzes reasoned by a Phenomenological methodology. With convergent analyzes for groups comprehending ideas expressed by subjects, we made conclusive considerations regarding the relevance of the proposed reflections, with an understanding of new pedagogical, epistemological and didatic values.
\end{abstract}

Keywords: Transformation Geometry, Phenomenology, Investigation, Collaboration, Graphic Software.

Revista de investigação e divulgação em Educação Matemática, Juiz de Fora, v. 2, n. 1, p. 06-25, jan./jun. 2018. 


\section{1) Introdução}

Trazemos aqui resultados e reflexões de uma pesquisa feita por nós em torno da Geometria. Consideramos a Geometria Escolar e a problemática de suas escolhas e organizações. Mais especialmente, trabalhamos com um modo, que diremos alternativo, de se trabalhar: a Geometria das Transformações.

Dizemos alternativo ao estatuto usual com o qual se trabalha a Geometria no Brasil, conforme se encontra na grande maioria de livros didáticos publicados e em programas disciplinares de escolas e sistemas de ensino. Esse estatuto, entendemos, dá conta de prosseguir na tradição que se constituiu para o ensino da Geometria, bem como é conveniente para os fins que se desenha o conhecimento geométrico - um deles, preparar o aluno para seleções ao ensino superior -, mas vem sendo objeto de reflexões críticas, donde emergem propostas alternativas.

Acreditamos na possibilidade de a Geometria das Transformações contribuir para uma formação geométrica mais ampla e saudável, e acreditamos em sua viabilidade curricular ao lado de outros modos. Ao desenvolver uma pesquisa com o intuito de compreender melhor essa possibilidade, descortinou-se para nós um horizonte de significações que nos oportunizou um novo olhar para a problemática da Geometria Escolar, conforme queremos compartilhar com os leitores deste artigo.

\section{2) A Geometria Escolar}

Tanto os Parâmetros Curriculares Nacionais quanto a nova Base Nacional Curricular Comum sugerem um nobre espaço de atuação para a Geometria, disciplina capaz tanto de ser um modelo de pensamento racional lógico organizado quanto de ir ao cotidiano das pessoas e dar um tratamento científico sobre os objetos físicos aí presentes. Mas a disciplinarização da Geometria é notoriamente um foco de dificuldades em se definir e cumprir seus objetivos.

Já no século XVIII, Clairaut - geômetra preocupado com o ensino, tendo publicado destacado livro-texto - mostrava a problemática do que e como ensinar Geometria, entendendo ele que "as dificuldades [...] provêm as mais das vezes do modo [...] com que esta se ensina. [...] Se principia sempre por um grande número de 
definições, de postulados, de axiomas [...] que [...] prometem [...] coisas áridas ao leitor" (CLAIRAUT, 1772, prólogo). Com esse autor, mostramos a longevidade da questão do ensino de Geometria, no caso numa fala que reclama do modo como uma rigidez axiomática ganha corpo.

Saltando para o século XX, encontramos o texto Perspectives on the teaching of Geometry for the 21st century (1995), redigido por participantes do ICMI, que descreve uma crise com relação tanto aos insucessos quanto à busca de uma nova identidade para a prática da Geometria Escolar. Para nós, o que mais se mostrou interessante nessa publicação foi o reconhecimento dos autores de um dos principais fatores que deixam a problemática da Geometria aberta: a extensa lista de possibilidades e tarefas para o fazer geométrico escolar.

Trabalhando nessas aberturas curriculares, vemos uma série de direções e pesquisas que vêm ocorrendo no Brasil, sempre apontando para variações do currículo de Geometria. Na esteira do Movimento da Matemática Moderna, traduzem-se, para edição brasileira, ideias de Dienes e Golding (1959), em publicação especialmente dirigida aos professores e professoras das séries iniciais, que trazem propostas de implementação de atividades geométricas envolvendo sentidos corporais e movimentos. O fundo matemático dessas atividades estaria voltado, também, para a Geometria das Transformações.

Omar Catunda e Martha Dantas são responsáveis por organizar na Bahia um movimento de renovação curricular para a Geometria. Em uma obra que capitaliza esse movimento (CATUNDA et al., 1988), é enfatizado que " a Geometria ensinada na maioria das escolas brasileiras é a Geometria de Euclides na sua apresentação milenar, excessivamente formal, e no seu aspecto exclusivamente de medida" (op. cit., p. 11). A partir dessa crítica, entre outras, passam a apresentar suas propostas de utilizar transformações geométricas desde o (atual) oitavo ano, sem requisitar, para isso, uma base axiomática formal.

$\mathrm{O}$ enfrentamento de uma onipresença do ensino de Geometria abarcando a tradição euclidiana está relativamente bem ocupado no cenário da pesquisa em educação no Brasil atual. Entendamos, aqui, que propor fora do euclidiano tem várias vertentes. Das mais consideradas, e que se veem mais representadas nos espaços de formação do futuro professor, estão as Geometrias Não-euclidianas caracterizadas pelo desvio 
estrutural com relação ao clássico quinto postulado euclidiano e decorrente proposição de modelos de espaços geométricos consistentes, como, por exemplo, o modelo de Riemann e o de Poincaré.

Mas, também, temos vertentes que podem ser consideradas não euclidianas quando representam alguma quebra tanto nas bases científicas quanto nas práticas didáticas geométricas. A Geometria das Transformações, como exemplo disso, a rigor lida com o mesmo espaço geométrico clássico, mas tem preocupações diferentes, uma vez que privilegia relações inter objetos, e não propriedades intrínsecas deles. Num sugestivo título, “Abandono da Geometria? Vivam as Geometrias!”, pesquisadores brasileiros registram práticas curriculares nas quais tantas geometrias podem ocorrer no espaço educacional, fazendo relato de experiências na escola básica, além de Transformações, com princípios da topologia e Geometria Projetiva (SILVA, BONGIOVANNI, VALENTE, 2011).

Geometrias distintas do escopo euclidiano são pouco presentes nos cursos de licenciatura em Matemática, uma vez que "aproximadamente 7\% das 166 Instituições formam professores que sabem da existência de outras geometrias além da euclidiana". (BARRETO; TAVARES, 2010, p. 2). Esse cenário muda quando se fala de estudos e pesquisas realizados em programas de pós-graduação, tanto na Educação Matemática quanto naqueles que enfocam o ensino de Matemática.

Em nossa pesquisa, nos dirigimos às possibilidades de se trabalhar com a Geometria das Transformações, ensejando contribuições para o cenário do ensino. A revisão bibliográfica que empreendemos reforçou uma intuição inicial nossa de que essa Geometria pode dividir espaço curricular com as práticas mais usuais.

\section{3) Breve entendimento da Geometria das Transformações}

Quando falamos em Transformações, nos reportamos aos fins do século XIX, quando a Matemática, a Geometria em especial, desenvolvia ideias mais amplas em sua estrutura e o estudo de invariações abria outros horizontes que aquele posto pelas congruências. A Geometria Projetiva teria aí um papel importante, uma vez que é seu fundamento estudar a projeção de um objeto, ou seção dele, sobre um plano qualquer, o que imediatamente traz os questionamentos sobre que caracteres invariam, nessa 
operação.

Mas, como observa Piaget e Garcia, é antes desse século, na álgebra, e depois naturalmente na Geometria Analítica, que a ideia de Transformação se presentifica: uma parábola passa a uma família pelo deslocamento que um número real variável causa, quando é associado à equação da cônica (PIAGET; GARCIA, 1987). Quando matemáticos como Poncelet, no início do século XIX, se empenham na tarefa de recuperar a posição que a Geometria havia deixado para a álgebra, são estudos acerca de transformações (projetivas ou de posição) em que ele se concentra para ampliar as possibilidades da Geometria pura.

São empreendimentos como esse que levam Felix Klein, ao publicar seu famoso Programa (KLEIN, 1872), à compreensão do que estava sendo realizado estruturalmente na Matemática de então: os invariantes, formando grupos para cada situação, ditavam geometrias correlatas. Junto com alguns contemporâneos, como Sophus Lie, ofereceram uma nova abordagem epistemológica para a Geometria, contribuindo para desdobramentos educacionais em novas práticas escolares.

Esses últimos pensadores nos levaram a ocuparmo-nos de possíveis direções, pesquisando como as Transformações podem trazer contribuições para o pensamento geométrico praticado nas escolas. Portanto, assumimos que estaríamos trilhando caminhos alternativos ao trabalho didático usual, este que é uma duplicação do modo de Euclides organizar a Geometria para se disciplinar a Geometria Escolar.

Dois aspectos epistemológicos se mostraram mais característicos para nós: as transformações indicam um pensamento interfigural, ou seja, mais interessam relações entre figuras do que propriedades intrínsecas, especialmente ligadas a medidas de seus elementos; outro aspecto é o da generalização, uma vez que são relações os objetos científicos que importam, chegando a se dizer que podemos abstrair as próprias figuras, descrevendo-se assim, em parte, o termo transfigural, da teoria garciapiagetiana.

Nosso interesse de pesquisa foram as possibilidades geométricas das transformações de posição, uma vez que nos ocupamos do grupo das isometrias desdobradas em simetrias, rotações e translações -, que deixam inalteradas as propriedades euclidianas das figuras, acrescido das transformações por homotetia, expandindo o primeiro grupo para o grupo das semelhanças.

A generalização conotada acima nos leva a uma ênfase no método mais do que 
em objetos particulares, uma característica evolutiva em todo o fazer histórico da Matemática. Para nossa intenção de operarmos essas ideias didaticamente, propusemos um princípio metodológico imediato e simples:

"Sendo f uma figura que contém A, a transformada f" dessa figura conterá o transformado do ponto $A^{\prime \prime}$,

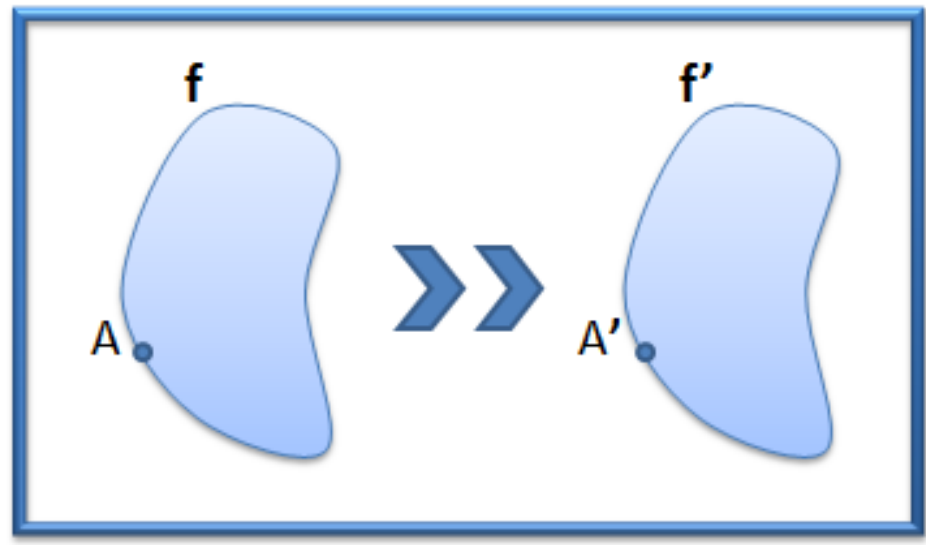

A obviedade desse princípio se abre, no entanto, a uma rica potencialidade de se pensar geometricamente em vista de buscar soluções para algumas situações propostas em forma de problemas. Com nossa experiência didática e a que tivemos com sujeitos de nossa pesquisa, vivenciamos que esse pensamento geométrico aplicado se revela não imediato, uma vez que os modos de pensar mais contumazes precisam ser confrontados para que as Transformações Geométricas possam se mostrar como alternativa a eles, evitando-se, assim, uma mitigação entre diferentes métodos.

$\mathrm{Na}$ exposição, a seguir, das atividades da pesquisa de campo que empreendemos junto a sujeitos de pesquisa, bem como em nossas análises, procuraremos mostrar uma experiência de vivenciamento de alternativas de pensar metologicamente sobre o espaço que dispomos geometricamente.

\section{4) Uma experiência em pesquisa geométrica com Transformações}

Nossos estudos preliminares nos levaram à seguinte interrogação: 'como aprendizes em colaboração constituem sentidos para a Geometria das Transformações 
com mediação de ferramentas dinâmicas?'. Pensando junto à Fenomenologia, uma interrogação é constituída ao longo da trajetória de compreensão do fenômeno focado pelos pesquisadores. Comumente, ela suscita mais uma abertura de horizontes trazendo outros aspectos de questionamento - que uma meta de resultados. $\mathrm{O}$ 'como' da pergunta já dispõe nosso maior intuito, pois não nos prendemos a checar apenas se os sujeitos constituiriam conhecimentos, nem a medir em quanto isso se daria.

Uma característica comum nas pesquisas fenomenológicas em geral e na Educação é tomar um objeto não o tornando um personagem central, uma vez que mais interessa como o sujeito expressa sua compreensão desse objeto. Assim, apesar de nosso foco ser a Geometria das Transformações, entendemos que qualquer proposta curricular deveria passar pela experiência de sujeitos num campo de pesquisa, concordando com Bicudo (2011, p. 30) quando diz que o sujeito é vivente num contexto particular e nesse ele encontra os meios imediatos para expressar sua compreensão sobre o que vive.

Para colocarmos em prática esse movimento de vivenciar junto a sujeitos, foram preparadas doze atividades de Geometria das Transformações, sendo três de cada tópico que consideramos: simetria, translação, rotação e homotetia. Elas comporiam o conjunto que seria trabalhado em situação próxima à de uma oficina. Entendemos a pertinência buscarmos alunos de uma licenciatura em Matemática como sujeitos, atendendo a alguns aspectos. Um primeiro se liga a estarmos juntos a futuros profissionais, podendo participar de sua formação e termos esses alunos como vetores de levar nossas propostas adiante. Outro aspecto é da preparação que os licenciandos escolhidos possuíam como pré-requisito para acompanharem o desenvolvimento das atividades geométricas. $\mathrm{O}$ local da pesquisa também contribuiu para nossas escolhas, uma vez que o curso contava com uma disciplina com ementa que abrigava conteúdos e metodologias alternativos.

Da pesquisa de campo participaram 6 sujeitos, que desenvolveram 8 das atividades em duplas em uma sala de aula assistida por software gráfico, no caso o Geogebra, durante 4 encontros. Em cada encontro foram abordadas duas atividades; uma terceira ficava para ser feita depois, podendo ser tarefa individual. Foram feitas gravações das ações dos sujeitos nos grupos, registrando-se gestos e falas, concomitante com registro das soluções gráficas por meio de captura da tela do computador com uso de software disponível gratuitamente (Action).

As atividades foram montadas a partir do interesse maior de poderem suscitar 
discussões entre os licenciandos, dentro do espírito que Ponte (2003), Frota (2005) e Onuchic e Allevato (2011) descrevem como Problemas e o decorrente ambiente pedagógico para suas Resoluções. A principal característica observada na montagem delas foi oferecer uma familiaridade geométrica, porém, uma não imediaticidade de solução. Seus textos propositivos traziam significados mais contextuais não só como proposta de serem mais motivadores, mas também de serem exigentes de uma interpretação matemática. Foram solicitadas soluções gráficas, tal como em aulas de Desenho Geométrico.

A atividade abaixo, a segunda do rol da pesquisa, exemplifica essas características, sendo interessante notar que o texto não faz indicações explícitas de qual transformação está envolvida:

\section{Atividade 2- TRIATLON}

Um treinador resolveu criar um treino diferenciado para o seu atleta de triatlon. No clube escolhido para os treinos, há duas piscinas redondas e o treinador quer que o atleta percorra, numa só reta e na direção das raias das piscinas, um trecho nadado na primeira piscina, um trecho corrido entre as piscinas e um último trecho nadado na segunda piscina, de modo que os dois trechos nadados somem d metros.

Onde terá que ser a largada para que o atleta nade $\mathbf{d}$ metros?

Desde nossa presença junto aos sujeitos e nas primeiras compreensões sobre o material com os dados gravados na pesquisa, sentimos a necessidade de ampliar nossa base teórica, quando refletimos sobre uma revisão de literatura acerca do Pedagógico, do Epistemológico e do Didático, que articulamos e tomamos como modos de compreender o ocorrido em campo. 
Abordamos o Pedagógico como em Oliveira (2017), quando "entendemos dele uma atinência a uma globalidade coimplicada, que se compatibiliza com a ideia de o humano como uma totalidade existencial, abarcando o ser vivente com o ser conhecedor" (OLIVEIRA, 2017, p. 36). A visão de uma experiência de conhecimento que extrapola a simples condição de se estar produzindo conhecimento científico permite estar com a ciência de maneira a trazê-la para ser um constituinte de nossa visão global do mundo.

Essa relação ampliada com a ciência implica tomá-la em compreensão genuína, e não apenas preocupar-se em conhecê-la em seus conceitos já estruturados segundo uma coisa já constituída. Contra essa preocupação, que consideramos alienante, vimos nossos sujeitos de pesquisa terem sido oportunizados de e oportunizarem um trabalho epistemológico, o de recompreender a Geometria que já conheciam e idealizavam no seu todo.

$\mathrm{O}$ fato de experenciarmos um trabalho não usual com Geometria, inclusive valorizando o espaço gráfico e o pensamento geométrico puro, possibilitou a vivência de valores epistemológicos ampliados. Encontramos nas referências de razão e sensibilidade, de Cifuentes (2003), nas de extensão do espaço gráfico para o corpo de quem o vivencia, de Paulo (2010) e nas referências de aspectos intuitivo, experimental e teórico que o espaço imediato permite, de Pais (1996), um conjunto de compreensões necessárias para repensarmos a aprendizagem geométrica advinda das Transformações.

O terceiro constructo teórico que realizamos se volta ao didático. Nossa experiência profissional e nossa concepção de espaço investigativo e colaborativo já nos predispunham a propor atividades dentro de um arranjo didático com abertura suficiente para abrigar ações, reflexões e diálogos que aguardávamos serem presentes entre os sujeitos. Entre outras, nossas referências buscaram ideias de Resolução de Problemas, como em Onuchic e Alevatto (2011), e de constituição de ambientes investigativos, como em Ponte (2003).

Até por estarem em um ambiente de formação profissional, nossos sujeitos conduziram o didático, estabelecendo-o, tornando-o uma tarefa pedagógica e, também, mostrando sua afinidade com a natureza de compreensão epistemológica empreendida. Como registrou Oliveira (2017), entendemos que a questão didática não se debruça sobre como a experiência de aprendizagem sobre objetos é uma relação da verdade para 
mim, mas "como minha experiência se liga à experiência que os outros têm dos mesmos objetos" (MERLEAU-PONTY, 1990, p. 48).

Para realizar as análises sobre os dados produzidos em campo perfizemos a trajetória comum em pesquisas fenomenológicas feitas em Educação Matemática no Brasil, nas quais, a partir de transcrição fiel dos registros das manifestações dos sujeitos e mediante uma interpretação isenta de valores teóricos estranhos ao ocorrido, é realizada, inicialmente, uma análise ideográfica. Esta se incumbe de compreender e enfatizar as ideias que os sujeitos doam ao pesquisador, que vive o horizonte aberto por sua interrogação. Ele registra, com texto próprio, essas ideias, enfatizando-as.

No nosso caso, as transcrições, que dão conta de uma imensa produção de falas e gestos, foram recortadas em cenas, recurso metodológico que considera o fluxo do desenvolvimento das manifestações e, nele, momentos significativos em torno de um tema focal favorecido pelos próprios sujeitos em ação: estes inauguram uma questão pertinente que se torna um tema para demais companheiros, que dele se ocupam até esgotá-lo em um certo nível de satisfação. O recorte é percebido e interpretado pelos pesquisadores quando analisam os dados, e cada cena, como um momento do fluxo global, é comprendido em atenção às ideias que a sustentam. Damos um pequeno exemplo de uma cena em nossa análise ideográfica:

\begin{tabular}{|c|c|c|}
\hline \multicolumn{3}{|c|}{ Primeira interpretação. } \\
\hline INTERAÇÃO & INTERPRETAÇÃO & IDEIAS \\
\hline $\begin{array}{l}\text { Os sujeitos leem a atividade juntos e } \\
\text { começa a interação na frente do } \\
\text { computador: } \\
\text { S1: Então a gente podia arbitrar um ponto } \\
\text { A nessa reta, montar um triângulo } \\
\text { equilátero, aí tem que pensar nisso só. Aí } \\
\text { depois tem que pensar em homotetia. } \\
\text { Entendeu? }\end{array}$ & $\begin{array}{l}\text { A apresentação surte efeito. O } \\
\text { sujeito identifica por meio da } \\
\text { leitura o que a atividade } \\
\text { propõe. } \\
\text { Uma trajetória metodológica } \\
\text { vai sendo articulada, dando-se } \\
\text { liberdade de se pensar em } \\
\text { rascunho. } \\
\text { Há uma preocupação da dupla } \\
\text { funcionar, no diálogo } \\
\text { matemático ocorrido. }\end{array}$ & $\begin{array}{l}\text { O horizonte geométrico é } \\
\text { habitado. } \\
\text { Utilização de estratégias para a } \\
\text { resolução. } \\
\begin{array}{l}\text { Diálogo científico posto; (um } \\
\text { pensamento matemático se } \\
\text { põe). }\end{array}\end{array}$ \\
\hline
\end{tabular}

Revista de investigação e divulgação em Educação Matemática, Juiz de Fora, v. 2, n. 1, p. 06-25, jan./jun. 2018. 
Uma mesma ideia pode ser suscitada por distintas manifestações, quando ela dá conta de várias situações que se assemelham ao olhar intencionado do pesquisador, que tem sempre sua interrogação norteando. Para a fenomenologia, a intencionalidade não significa ter um objetivo e agir e pensar em sua atinência. Doutro modo, significa estar dirigido, atento à única fonte de significação que os dados permitem: a manifestação genuína dos sujeitos.

Metodologicamente, após a interpretação de todas as ideias percebidas pelos pesquisadores, passa-se a um processo de convergência de significados mais abrangentes. Não falamos em categorizações, a fim de evitar uma confusão teórica com as metodologias que cuidam de levar as análises a uma cristalização de resultados. A fenomenologia chama esse processo convergente de análise nomotética, em que a raiz nomos nos traz o sentido de uma nomeação que assegura a singularidade de um significado convergido, ao mesmo tempo tendo o compromisso de se tornar um termo reconhecido pela comunidade científica afim.

Nossas análises nomotéticas ocorreram em dois momentos de convergência: o de Ideias Nucleares e o de Ideias Nucleares Abrangentes, estas que formaram sete grupos: Valores Pedagógicos Vividos na Pesquisa; Modos Didáticos Emergentes da Experiência Vivida na Pesquisa; Modos de Realizar, Compreender e Conceber a Ciência na Experiência Vivida; Modos de viver o Software; GT como Abertura de Horizontes e $O$ afetar-se na Experiência Vivida. Por meio também de um tabelamento, fizemos o movimento de análise, como no exemplo a seguir:

\begin{tabular}{|c|c|c|}
\hline Ideias & Ideias Nucleares & $\begin{array}{l}\text { Ideias Nucleares } \\
\text { Abrangentes }\end{array}$ \\
\hline Interação e colaboração & \multirow{3}{*}{$\begin{array}{lll}\begin{array}{l}\text { Diálogo } \\
\text { pedagógico }\end{array} & \text { como } & \text { valor } \\
\end{array}$} & \multirow{5}{*}{ 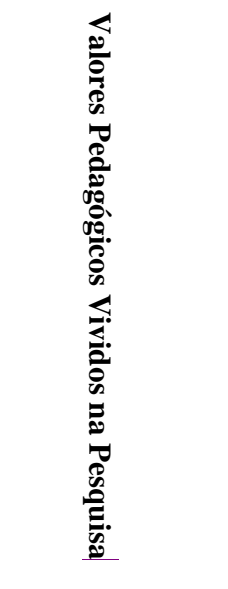 } \\
\hline $\begin{array}{l}\text { Argumentação apropriando-se de conhecimento } \\
\text { teórico e movimento. }\end{array}$ & & \\
\hline $\begin{array}{l}\text { O estar em dupla proporcionou uma ajuda na } \\
\text { decisão de onde partir. }\end{array}$ & & \\
\hline $\begin{array}{l}\text { Utilização de estratégias facilitadoras para a } \\
\text { resolução. }\end{array}$ & \multirow{2}{*}{$\begin{array}{l}\text { Conhecimento como encontro } \\
\text { e horizonte }\end{array}$} & \\
\hline $\begin{array}{l}\text { Movimento gestual ajuda na constituição do } \\
\text { conhecimento }\end{array}$ & & \\
\hline
\end{tabular}

Revista de investigação e divulgação em Educação Matemática, Juiz de Fora, v. 2, n. 1, p. 06-25, jan./jun. 2018. 


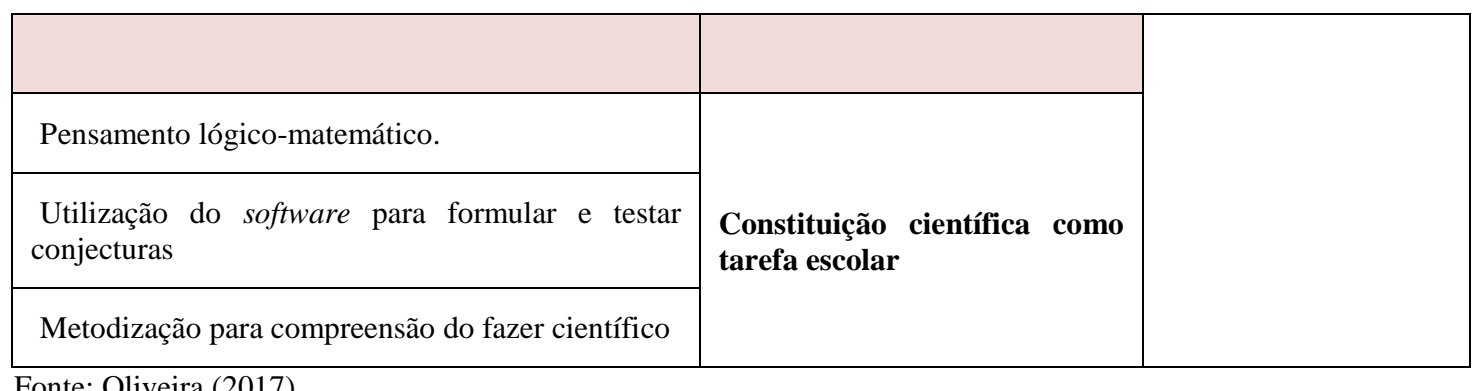

Fonte: Oliveira (2017)

Ao acompanhar o exemplo acima, é preciso considerar que os nomes escritos só fazem sentido com a remissividade que se impõe desde os núcleos de maior abrangência até as manifestações originais dos sujeitos. Esse caráter metodológico pode ser objeto de crítica por quem está mais envolvido com resultados categóricos - também abrangentes - mais explicativos do que compreensivos, mas essa é a contribuição metodológica que a Fenomenologia traz: as ideias nucleares abrangentes são, mais que resultados, pontos de partida para novas compreensões, como para o próprio pesquisador que poderá tecer considerações nas quais legará suas novas compreensões do fenômeno à sua comunidade científica.

Aproveitando a convergência que a tabela acima expõe, esboçaremos uma explicitação do nosso movimento metodológico que a constituiu. Como início, de acordo com o que já dissemos neste texto, elaboramos uma compreensão do pedagógico a partir das primeiras interpretações que fizemos, e ela foi se fazendo presente ao lidarmos com os dados registrados na pesquisa.

Acompanhando as colunas da tabela acima, vemos que os valores pedagógicos vêm de três distintos grupos de ideias. A ênfase no diálogo mostra a condição existencial de estar com o outro mediado pela tarefa de uma compreensão científica, definindo uma ontologia do ser aprendiz que não é mais a do estudante que vê, lê e aprende, mas o que busca no exercício das linguagens - oral, da escrita matemática, gráfica, gestual - o conhecimento se fazendo no movimento de interação e colaboração.

O segundo grupo acima enfatiza o sentido de se propor a constituição do conhecimento interagido como encontro de companheiros, quando eles podem conjecturar, fazer testes, usar gestos com significados de movimentos geometrizáveis. Estar com o outro, dispor os movimentos intelectual e corporal abre horizontes pedagógicos abrangentes de conhecimentos constituídos significativos e não focados em uma verdade matemática preposta, mas carregados de conotações contextuais. 
O terceiro grupo revela um horizonte pedagógico no qual a ciência vivida nas experiências da pesquisa é tomada de outra perspectiva, comparando-se com os modos mais tradicionais. Mesmo os necessários fundamentos lógico-matemáticos vêm em forma de acordo, e não como pressupostos exteriores àquela experiência. O uso não dirigido do software permite que tanto as ações empíricas quanto as conjecturais ampliem a consideração do rigor que se requer na constituição do conhecimento. Nesse horizonte, há um deslocamento do que se considera importante, pois os sujeitos compreendem que pesquisar caminhos e métodos de solução matemática é tão pertinente quanto se ratificar ou constituir objeto ou conceito.

Esses três grupos nos ajudam a compreender que os valores pedagógicos não são apenas grandes metas que norteiam as práticas escolares, mas estão presentes como tarefas do cotidiano escolar, constituindo-se junto com elas.

Os seis demais grupos de Ideias Nucleares Abrangentes reforçam a visão geral de que em nossos resultados sempre o tema matemático enfocado ocorre numa perspectiva do vivido tal como os sujeitos o experienciaram. Neste texto, vamos relevar cinco deles, apenas enfatizando o que mais diretamente diz respeito à Geometria das Transformações.

\section{"A Geometria das Transformações como Abertura de Horizontes"}

O subtítulo acima é o nome que demos a um dos grupos de ideias abrangentes no qual mais diretamente analisamos a pesquisa feita em torno do tema geométrico que elegemos. Nesse âmbito também se afirmam os valores com os quais se desenvolveram as ações dos nossos sujeitos, e o conhecimento geométrico constituído é imediatamente tributário do ambiente didático oportunizado: situações postas como modo investigativo, interações colaborativas, uso de recursos de expressão variados (rascunhos, régua e compasso, softwares) e valorização de todas as estratégias sugeridas pelos sujeitos.

Presentes diretamente nas ações da pesquisa de campo, temos apontamentos a ser registrados. O primeiro que relatamos aqui é uma persistente inicial resistência dos sujeitos em pensar a Geometria fora dos padrões a que estão acostumados. Percebemos a intenção deles de se apegar ao esquema de pensamento segundo o qual trabalham 
soluções procurando propriedades de figuras e correspondências entre elas que pudessem interceder, especialmente relações métricas angulares ou lineares. A novidade naturalmente proposta, o pensamento sobre movimento de figuras - rotacionar, transladar, simetrizar, homotetizar -, foi com alguma delonga aceita e trabalhada como um método distinto de espacializar, ou de se pensar geometricamente.

Essa constatação, que vemos importante como resultado de pesquisa, foi, no entanto, crítica à nossa própria intenção de oportunizar em poucas sessões, e ao longo de poucas semanas, uma adesão a um novo pensar metodológico e científico que requer um mínimo de maturação.

Mas a maioria dos sujeitos, ao final, compreendeu o diferencial das Transformações, aceitando sua contribuição. Para isso - entendemos da pesquisa feita foi importante o trabalho com o espaço gráfico, especialmente o oportunizado pelo software. Uma das características do modo tradicional de se trabalhar a Geometria, sabemos, é as figuras situadas servirem mais como um apoio visual para que um aprendiz vislumbre uma propriedade ainda oculta e, a partir disso, possa partir para um registro matemático alheio a elas, este comumente sendo algébrico. O espaço gráfico que propusemos era pleno, no sentido de que ele expunha os dados interpretados e era o espaço para solução, de caráter sintético, imediato das formas e movimentos.

Tomamos, aqui, a atividade 5 proposta aos sujeitos, que, antes de iniciadas as ações de campo, tiveram apresentações mais teóricas do método e das transformações em si mesmas. A rotação, embora incógnita, era a transformação mais indicada a ser trabalhada nessa atividade, acrescida da necessidade de mais uma transformação por homotetia. Mostraremos alguns recortes de como uma dupla de sujeitos - S1e S2 investigou a situação proposta, desde a interpretação até uma solução. Essa atividade foi proposta diretamente num aplet e, como veremos, a dinâmica do software foi importante para o desenvolvimento. 


\section{ATIVIDADE 5: VIVEIRO - Dado o applet}

Antônio precisa construir um viveiro triangular equilátero, tendo como vértices três mourões: A, B e C. Para aproveitar o espaço, ele considerou que B e C ficassem juntos aos muros das margens das ruas São José e Batista.

No encontro dos muros ( Q ), há uma fonte d'água que servirá de irrigação para o viveiro. Um dos pontos de irrigação será em $\mathrm{P}$ que pertence à cerca $\mathrm{BC}$, e o outro será em $\mathrm{A}$. Por questão de economia P e A estarão alinhados com a fonte principal Q.

Ajude Antônio a construir esse viveiro.

"Os sujeitos leem a atividade juntos e começa a interação na frente do computador:

S1: Então a gente podia arbitrar um ponto A nessa reta, montar um triângulo equilátero, aí tem que pensar nisso só. Aí depois tem que pensar em homotetia. Entendeu?

S1: A gente arbitra um ponto aqui assim (aponta na tela do computador), ou aqui (na reta construída no computador) vou por aqui assim e monta o triângulo equilátero aqui, pq? depois a gente ou volta ou vai com ele, pode ser?

S2: agora vê aí, um polígono regular.

S1: Aí como é que é? Seleciona primeiro dois pontos e a quantidade de vértices... (lendo no software) Não, não pode ser assim, tem que construir aqui.

S2: É, é isso que eu tô pensando (...) é, vai ter que construir ele.

S1: $E$.

S2: É, porque senão ele vai jogar... não vai jogar nessas duas (retas).

S1:(silêncio, olhando para a tela do computador pensativo): Puxa, danou!

Nesse pequeno recorte vemos que a dupla de resolvedores dialoga e abre um horizonte de pesquisa geométrica para o qual concorrem uma já certa experiência deles com o pensamento de transformações - por jogarem com uma solução parcial auxiliar

Revista de investigação e divulgação em Educação Matemática, Juiz de Fora, v. 2, n. 1, p. 06-25, jan./jun. 2018. 
em posição tal que depois eles poderiam 'ir ou voltar com ela' -, uma atualização de conhecimentos pregressos e uma ativa interação geométrica com o software, que, aliás, foi ágil em mostrar que alguma coisa não tinha dado certo.

Eles vão desenvolvendo sua investigação incontinente, abrindo nova frente para o diálogo mediado pelo computador e de gestos e movimentos corporais geométricos.

S2: Joga um ponto aqui, (mostrando uma distância com o polegar e o indicador de uma mão, na tela do computador) aí a gente vai ter que achar uma distância que seja igual a essa daqui, aqui... Mas aí aqui não vai ser igual.

S1: Tô pensando em fazer pra lá. Porque o A tá aqui... num dá, P e A estão alinhados com a fonte.

S4: Então o A está nessa reta mesmo. Mas até aqui assim mesmo; mas como é que faz pra traçar aqui embaixo?

S1: Esse aqui, o B, é um dos vértices, né? (faz um vê com os dedos indicador e médio, e fica olhando e movimentando para tentar encaixar o vê no desenho da tela).

$S 2: \dot{E}$.

S1: Então, se eu tenho um ponto nessa reta aqui, o ponto nessa (outra) reta ... $60^{\circ}$, né ?!.

Uma propriedade angular faz atinar um dos sujeitos a pensar em rotação, o que ele articula para si, enfatizando o valor em graus para seu companheiro, que prontamente percebe a perspectiva aberta:

S2: É rotacionar o vértice...

S1: ... o ponto

S2: Em torno desse ponto (B).

S1: Mas essa reta é rotacionável? É! Então rotaciona aqui. (utilizando a ferramenta do software)

S2: É porque a reta tá em volta, né? Rsrsrs, dá impressão....

A compreensão global do que se tinha a fazer foi assegurada por uma confiança no método, configurada no diálogo entre os resolvedores. Com isso, a sequência de passos da solução, abaixo, foi retrato de uma lucidez constituída em conjunto: 


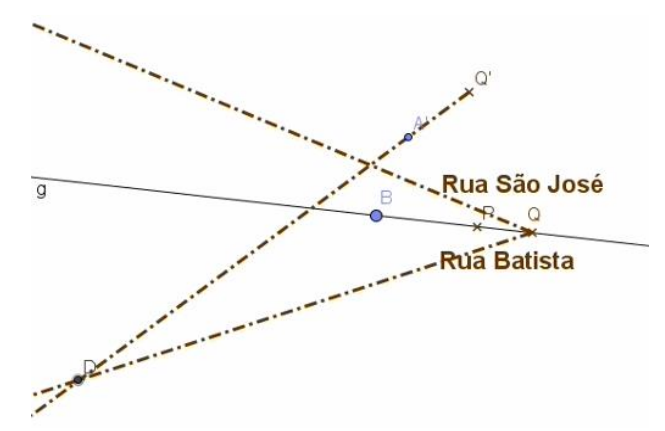

Arbitrado na reta $\mathrm{PQ}$ um ponto $\mathrm{B}$, vértice de um triângulo equilátero com os outros dois vértices nas ruas dadas, a dupla rotaciona em torno dele a rua São José, usando recursos do software, achando o ponto D.

Definido o lado BD, constrói-se o triângulo equilátero auxiliar BD`D, com D’ construído mediante rotação de $\mathrm{D}$ em torno de B.
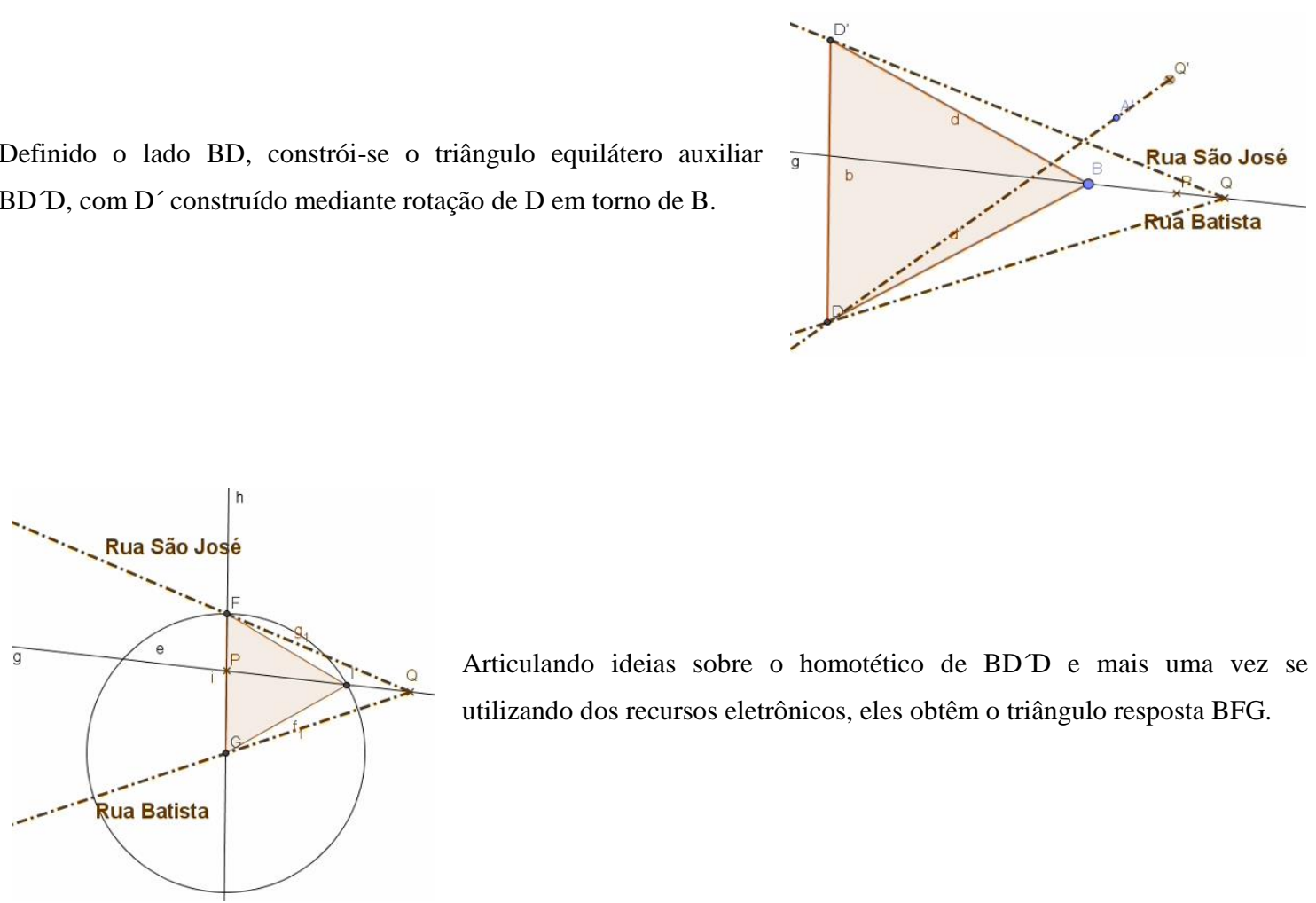

Articulando ideias sobre o homotético de BD`D e mais uma vez se utilizando dos recursos eletrônicos, eles obtêm o triângulo resposta BFG.

Essa sequência mostra uma organização na desenvoltura que é sinal de uma compreensão do método e das possibilidades do pensamento de transformações, inclusive com o princípio geral que enfatizamos neste texto: se o vértice da rua Batista é transformado do vértice da rua São José, então aquele está na transformada da rua São José. Os sujeitos revelam as ideias que convergiram para esse grupo de Ideias Nucleares Abrangentes que nomeamos acima, aludindo a uma abertura de horizonte ofertado pela Geometria das Transformações. Esse horizonte é ocupado cinestesicamente quando eles empreendem seus movimentos dirigidos a significar conhecimentos, quando abrem um 
diálogo profícuo e quando posicionam a Geometria que estão descortinando no horizonte mais amplo de todas as geometrias que conhecem.

Com uma solução conseguida, a dupla de resolvedores ainda seguiu fazendo observações, algumas sugestionadas pelas operações potencializadas no software; uma delas foi a análise de o problema admitir duas soluções, quando sugeriram aos pesquisadores que se podia acrescer à proposição da situação a condição de se chegar ao viveiro de menor (ou de maior) perímetro.

\section{5) Algumas considerações}

Nossos sujeitos nos mostraram que a Geometria das Transformações é um modo possível de ser trabalhada a Geometria Escolar, em convívio com as práticas mais usuais. Estas, como vimos em nossa experiência de pesquisa, garantem um solo geométrico que dá familiaridade para se lidar com relações métricas a partir das quais a direção aberta pelas Transformações pode ser um caminho para mais amplitude curricular em Geometria.

As Transformações abrem um horizonte peculiar de pesquisa geométrica, o que é referenciado em situações geométricas próprias, tal como procuramos trazer nas atividades propostas em nossa pesquisa de campo. Essa característica de distinção foi várias vezes percebida e verbalizada por nossos sujeitos, quando reconheciam a importância da potencialidade da Geometria das Transformações para o seu futuro como professores. Entendemos que as atividades que propomos são, quanto à sua natureza e requisitos, indicações para um possível trabalho no ensino médio, no qual os alunos já perfizeram certa trajetória geométrica e já tem mais maturidade para lidar com a novidade das transformações.

Os resultados das análises corroboram ser a Geometria das Transformações uma geometria do movimento, uma vez que a mudança de posição de figuras - mesmo duas figuras homotéticas não iguais - são vistas numa relação de movimento que leva uma à outra. Analisamos que um software dinâmico tem a natureza que abriga o movimento, e seus recursos o tornam um operador condizente com aquilo que aqui chamamos de pensamento de transformação. Esse pensamento dá vazão à motricidade do resolvedor de problemas, que age junto com as faces do computador. 
Do ponto de vista metodológico, vemos uma importância de se trabalhar com modos alternativos de geometria. A tradição dos modos mais usuais, entendemos, acaba escondendo que nossa geometria elementar também tem seus métodos, e experiências tais como as que trazemos propostas podem reviver a condição natural do homem como ser que cria métodos, permitindo mais uma oportunidade de se refletir sobre a matemática que habitamos.

\section{Referências}

BARRETO, M. D. S.; TAVARES, S. Do mito da Geometria Euclidiana ao ensino das Geometrias Não Euclidianas. In: Anais do X Encontro Nacional de Educação Matemática, Cultura e Diversidade. Ilhéus: SBEM, 2010. p. 1-10.

BICUDO, M. A. V. A. A pesquisa qualitativa olhada para além de seus procedimentos. In: BICUDO, M. A. (Orgs.). Pesquisa Qualitativa segundo a visão fenomenológica. São Paulo: Cortez, 2011.

CATUNDA, O. et al. As transformações geométricas e o ensino da Geometria. Salvador: Centro Editorial e Didático da UFBA, 1990.

CIFUENTES, C. C. Fundamentos Estéticos da Matemática - da habilidade à sensibilidade. In: Bicudo, M A V. (Org.) Filosofia da Educação Matemática: Concepções e Movimento. Brasília: Plano Editora, 2003. p. 59/79.

CLAIRAUT, M. Elementos de Geometria. Lisboa: Regia Officina Typografica, 1772.

DIENES, Z., GOLDING, E. Exploração do Espaço. São Paulo: Melhoramentos, 1959.

FROTA, M.C.R. Experiência matemática e investigação matemática. V CIBEM, Porto, Portugal, jul. 2005. Disponível em: http://www.matematica.pucminas.br/Grupos de Trabalho/Grupo PINEM> Acesso em: 18 out. 2016.

INTERNATIONAL COMMISSION ON MATHEMATICS INSTRUCTION - ICMI. Perspectives on teaching of geometry for the 21st century. In: Education Studies in mathematics, v. 28, 1995. 
KLEIN, F. O programa de Erlangen. in: FERNANDES, N. C. (Trad.) O programa de Erlangen de Félix Klein: considerações comparativas sobre as pesquisas geométricas modernas. São Paulo: Ifusp, 1984, 2-78.

MERLEAU-PONTY, M. O Primado da percepção e suas consequências filosóficas. Campinas: Papirus, 1990.

OLIVEIRA, D. B. S. A constituição de conhecimento colaborado em geometria das transformações com ferramentas dinâmicas. Dissertação de Mestrado. 2017.

ONUCHIC, L. R.; Allevato, N. S. G., Pesquisa em Resolução de Problemas: caminhos, avanços e novas perspectivas. Bolema, Rio Claro (SP), v. 25, n. 41, p. 73 98, dez. 2011

Pais, L. C. Intuição, Experiência e Teoria Geométrica. Zetetiké, Campinas, SP. v.4, n. 6, p. 45-63. jul/dez. 1996

PAULO, R. M. O significado dos diagramas na produção do conhecimento geométrico. In: Bicudo, M. A. V. (Org.) Filosofia da Educação Matemática: fenomenologia, concepções, possibilidades didático-pedagógicas. São Paulo: Ed. Unesp, 2010. P. $169 / 192$.

PIAGET, J, ; GARCIA, R. Psicogênese e História das Ciências. Traduzido por Maria F. M. R. Jesuíno. Lisboa: Publicações Dom Quixote, 1987.

PONTE, J. P. Investigar, Ensinar e Aprender. Actas do ProfMat (CD-ROM, p.25-39). Lisboa: APM, 2003.

SILVA, MCL. BONGIOVANNI, V. VALENTE, WR. Abandono da Geometria? Vivam as Geometrias! Belém: SBEM-PA, 2011.

Recebido em: 03 de junho de 2018.

Aprovado em: 25 de junho de 2018. 